\title{
Quality Assessment of 25(OH)D, Insulin, Total Cholesterol, Triglycerides, and Potassium in 40-Year-Old Frozen Serum
}

\author{
Monica Leu, ${ }^{1}$ Kirsten Mehlig, ${ }^{1}$ Monica Hunsberger, ${ }^{1}$ Åsa Torinsson Naluai, ${ }^{2,3}$ \\ Kaj Blennow, ${ }^{4}$ Henrik Zetterberg, ${ }^{4,5}$ Cecilia Björkelund, ${ }^{6}$ and Lauren Lissner ${ }^{1}$ \\ ${ }^{1}$ Section for Epidemiology and Social Medicine, Institute of Medicine, University of Gothenburg, P.O. Box 453, \\ 40530 Gothenburg, Sweden \\ ${ }^{2}$ Sahlgrenska Biobank, Sahlgrenska University Hospital, 41345 Gothenburg, Sweden \\ ${ }^{3}$ Department of Biomedicine, Sahlgrenska Academy, University of Gothenburg, 41345 Gothenburg, Sweden \\ ${ }^{4}$ Department of Psychiatry and Neurochemistry, Institute of Neuroscience and Physiology, University of Gothenburg, \\ 43180 Mölndal, Sweden \\ ${ }^{5}$ UCL Institute of Neurology, Queen Square, London WC1N 3BG, UK \\ ${ }^{6}$ Department of Primary Health Care, Institute of Medicine, University of Gothenburg, 40530 Gothenburg, Sweden
}

Correspondence should be addressed to Monica Leu; monica.leu@gu.se

Received 1 November 2014; Revised 26 January 2015; Accepted 28 January 2015

Academic Editor: Jaume Marrugat

Copyright (c) 2015 Monica Leu et al. This is an open access article distributed under the Creative Commons Attribution License, which permits unrestricted use, distribution, and reproduction in any medium, provided the original work is properly cited.

\begin{abstract}
Background. Many longitudinal epidemiological studies collect specimens into biobanks to investigate how biomarkers predict future disease. In 1968-1969, the Population Study of Women in Gothenburg (PSWG) established a biobank of serum samples. Objective. To examine the validity of 25-hydroxyvitamin $\mathrm{D}(25(\mathrm{OH}) \mathrm{D})$, total cholesterol, triglycerides, insulin, and potassium after 40 years of storage at $-20^{\circ} \mathrm{C}$ in terms of relative and absolute agreement. The quality of these markers under such condition has not been previously investigated. Methods. Baseline and remeasured levels were compared in selected samples through percentage change, correlation, and regression. 25(OH)D levels, not assessed at baseline, were compared by season, by BMI, and longitudinally over six years. Results. Despite some lack of absolute agreement, Spearman correlations were $>0.7$ and statistically significant for all biomarkers. The 1968-1969 25(OH)D correlated with BMI $(r=-0.45, P=0.05)$ and with levels six years later $(r=0.85, P<0.001)$. Summer $25(\mathrm{OH}) \mathrm{D}$ was higher than winter 25(OH)D $(P=0.02)$. Conclusion. For all markers, baseline and remeasured levels exhibited high relative agreement. 25(OH)D was comparable with expected levels on fresh blood and varied with season. In future studies, PSWG individuals will be ranked according to these markers in order to predict incidence of disease.
\end{abstract}

\section{Introduction}

Many of today's modern epidemiological studies involve the collection and storage of biological specimens in biobanks. When participants are also followed prospectively researchers have an excellent means for investigating how biomarkers contribute to disease etiology. Indeed, during the biobanking and clinical follow-up period, many novel biomarkers or better assay formats could be identified to provide important information for the study. Some examples are the Rotterdam Study, ongoing since 1990 [1]; the UK Biobank [2]; INTERGENE [3] initiated in 2001; LifeGene [4]; and EpiHealth [5] in Sweden. One of the earliest such initiatives was the Population Study of Women in Gothenburg (PSWG), started in 1968-1969, that originally aimed to identify risk factors for cardiovascular disease, diabetes, and mental illness during the transition from before to after menopause. Recently, midlife homocysteine levels in frozen serum samples from the baseline were examined in relation to the development of late-life dementia and the development of coronary heart disease [6, 7]. Given the 40-year storage in the PSWG biobank, in $-20^{\circ} \mathrm{C}$ temperature, a certain degree of sample deterioration is expected. It is thus important to assess the validity of new analytes before using them in future studies. In the present study, we examine the validity of selected biomarkers that were originally measured in fresh 
blood, specifically total cholesterol, triglycerides, insulin, and potassium, as well as one that was never previously measured, namely, 25-hydroxyvitamin $\mathrm{D}(25(\mathrm{OH}) \mathrm{D})$. We explore deterioration in terms of changes in absolute values at reanalysis compared to original assessments. More importantly for epidemiologists, we investigate whether, despite changes in absolute values, individuals can be ranked correctly according to their risk of disease based on these markers.

\section{Methods}

2.1. Population. PSWG is a longitudinal study that included 1462 women representative of the population aged 38-60 years living in Gothenburg in 1968-1969 [8, 9]. At baseline, data was collected through clinical examinations and face to face interviews covering history of physical and mental disease, lifestyle, social circumstances, and reproductive history. The participants have been followed up in six examinations, between 1974 and 2010. Due to the long follow-up, high participation rates and thorough mapping of nonparticipants, as well as morbidity and mortality register data, outcomes can be examined up to an advanced age.

2.2. Blood Samples. At baseline, $120 \mathrm{~mL}$ blood was drawn from each participant. A small quantity was used for immediate analyses and the remainder was allowed to clot at room temperature for 2-3 hours. After coagulation, the blood was centrifuged and the serum separated. The serum was divided in $2.5 \mathrm{~mL}$ snap cap covered polystyrene cups enclosed together in small batches in firmly tied plastic bags and stored at $-20^{\circ} \mathrm{C}$.

2.3. Material. At the start of the study (1968-1969), analyses on fresh blood for total cholesterol, triglycerides, and potassium were performed in all participants. At the reanalysis of these biomarkers in 2012, we randomly selected 26 frozen samples from the baseline examination and compared the new values with the original values.

A different assessment strategy was used for insulin, which was originally measured only in the women aged 50 at the study initiation [10]. The actual screening took place within half a year from the baseline examination. The insulin levels of these women varied between 3 and $47 \mathrm{mU} / \mathrm{L}$, including 29 unique integer values. In 2012, we randomly chose one frozen sample among all women that had the same integer value at the original screening, thus resulting in 29 samples to be reanalyzed.

Unlike the previous biomarkers, vitamin D was not analyzed at baseline and, consequently, there were no original values to compare with. In 2013, 20 frozen samples from the baseline were selected to ensure maximum $25(\mathrm{OH}) \mathrm{D}$ variability, which is mainly influenced by season and BMI $[11,12]$. We selected women examined at baseline in March or April (end of winter) when 25(OH)D levels are lowest in the Northern hemisphere and September when $25(\mathrm{OH}) \mathrm{D}$ levels are at their peak [13]. Moreover, the selection covered a broad BMI range. Among the 20 women, six were examined in September, with $19<\mathrm{BMI}<29 \mathrm{~kg} / \mathrm{m}^{2}$, and 14 at the end of the winter, with $18<\mathrm{BMI}<32 \mathrm{~kg} / \mathrm{m}^{2}$, and were aged 38 or 46 years. Additionally, to assess the temporal stability of this marker, the $25(\mathrm{OH}) \mathrm{D}$ analyses were repeated for these 20 study participants in serum stored from a subsequent examination six years later in 1974-1975.

The sampling characteristics for all parts of the study together with the laboratory methods at baseline and at reanalysis are summarized in Table 1.

2.4. Laboratory Assessments. For the 1968-1969 analyses, we were able to identify the laboratory methods for all biomarkers reported here. Specifically, total cholesterol was determined using an automated method [14]; triglycerides were measured with a semiautomated method applied on the isopropanolic filtrate of serum [15]; potassium was determined by flame photometry [16]; and insulin was assessed by a double antibody method [10].

By 2012-2013, when our reanalyses were performed, current laboratory methods were used. None of the frozen samples was previously subjected to thaw-freeze cycles. Thus, cholesterol, triglycerides, and potassium were analyzed with a Cobas 8000 instrument after the samples were subjected to a high speed centrifuge protocol $(15000 \mathrm{~g})$, at the Clinical Chemistry Laboratory, Sahlgrenska University Hospital, Gothenburg. Insulin was determined with a Cobas 6000 Roche Diagnostics instrument (Roche Diagnostics, Mannheim, Germany), using the Insulin Elecsys, art nr 12017547 122, as the reagent, and the Sandwich-type immunoassay ECLIA method, at Östra Hospital, Gothenburg. For vitamin D, the samples from both examinations were analyzed simultaneously, with a Cobas e601 instrument that uses the Roche Diagnostics vitamin D total assay and a competitive ECLIA protein-binding assay. The assay employs a vitamin $\mathrm{D}$ binding protein as a capture protein, which binds to both $25(\mathrm{OH}) \mathrm{D}_{3}$ and $25(\mathrm{OH}) \mathrm{D}_{2}$. Intra- and interassay coefficients of variation were below $5 \%$. These latter analyses were performed at the Clinical Chemistry Laboratory, Sahlgrenska University Hospital, Mölndal. The analysis of new biomarkers that were not originally assessed in the beginning of the study was approved by the Regional Ethics Committee in Gothenburg.

2.5. Statistical Analyses. For all markers, we examined both the relative agreement and the absolute agreement between two sets of measurements (i.e., original and reanalyzed). The relative agreement was tested with Spearman's correlation coefficient. For vitamin D specifically, we used the partial Spearman correlation with adjustment for a potential change in the season of extraction between 1968-1969 and 1974-1975. This was necessary as the examination of a given participant did not always take place in the same month at both visits (the adjustment accounted for a summer-to-winter, winterto-summer, or no change). To test for $25(\mathrm{OH})$ seasonal differences, we used the Mann-Whitney $U$ test. Moreover, the degree of sample alteration due to storage was explored in linear regression models, with marker levels in the most recently analyzed serum being the dependent variable and the earlier measurements being the independent variable.

Regarding absolute values, each set of measurements was described in terms of range, median, mean, and standard 
TABLE 1: Summary of sampling strategies and laboratory methods for assessing validity of biomarkers in 40-year-old serum.

\begin{tabular}{|c|c|c|c|c|c|}
\hline \multirow{2}{*}{ Marker } & \multirow[t]{2}{*}{$n^{\mathrm{a}}$} & \multicolumn{2}{|c|}{$\begin{array}{l}\text { Baseline (1968-1968) } \\
\text { analysis on fresh blood }\end{array}$} & \multicolumn{2}{|c|}{ Reanalysis $2012-2013$ on frozen serum from baseline } \\
\hline & & $\begin{array}{l}\text { Period of } \\
\text { assessment }\end{array}$ & $\begin{array}{l}\text { Laboratory } \\
\text { assessment }\end{array}$ & Sampling strategy & Laboratory assessment \\
\hline $\begin{array}{l}\text { Substudy I: total } \\
\text { cholesterol, } \\
\text { triglycerides, } \\
\text { and potassium }\end{array}$ & 26 & Baseline & $\begin{array}{l}\text { Automated } \\
\text { method }(\mathrm{Ch}), \\
\text { semiautomated } \\
\text { method }(\mathrm{Tg}), \\
\text { and flame } \\
\text { photometry } \\
\text { (potassium) }\end{array}$ & Random & $\begin{array}{l}\text { Cobas } 8000 \text { Roche Diagnostics } \\
\text { instrument }\end{array}$ \\
\hline $\begin{array}{l}\text { Substudy II: } \\
\text { Insulin }\end{array}$ & 29 & $\begin{array}{l}\leq 6 \text { months from } \\
\text { baseline }\end{array}$ & $\begin{array}{l}\text { Double } \\
\text { antibody } \\
\text { method }\end{array}$ & $\begin{array}{l}\text { Representative of the } \\
\text { distribution values } \\
\text { from the baseline } \\
\text { assessment }\end{array}$ & $\begin{array}{l}\text { Sandwich-type immunoassay } \\
\text { ECLIA method; Cobas } 6000 \\
\text { Roche Diagnostics instrument }\end{array}$ \\
\hline $\begin{array}{l}\text { Substudy III: } \\
\text { vitamin D }\end{array}$ & 20 & NA & NA & $\begin{array}{l}\text { Representative of the } \\
\text { summer-winter } \\
25(\mathrm{OH}) \mathrm{D} \text { variability } \\
\text { at baseline } \\
\text { Analyses repeated on } \\
\text { frozen serum from } \\
\text { subsequent } \\
\text { examination, baseline } \\
(+) 6 \text { years }\end{array}$ & $\begin{array}{l}\text { Roche Diagnostics vitamin D } \\
\text { total assay and an ECLIA } \\
\text { protein-binding assay for } \\
\text { capturing both } 25(\mathrm{OH}) \mathrm{D}_{3} \text { and } \\
25(\mathrm{OH}) \mathrm{D}_{2} ; \text { Cobas e } 601 \text { Roche } \\
\text { Diagnostics instrument }\end{array}$ \\
\hline
\end{tabular}

${ }^{a} n$ represents the number of subjects that were assessed both at baseline and at reanalysis (substudy I and II) or the number of subjects assessed only at reanalysis (substudy III).

TABLE 2: Descriptive statistics, percentage of change, and correlation for serum concentrations measured in the same 26 subjects (total cholesterol, triglycerides, and potassium) and 29 subjects (insulin), respectively, in 1968-1969 and 2012.

\begin{tabular}{|c|c|c|c|c|c|c|c|c|c|}
\hline & \multirow[t]{2}{*}{$n$} & \multicolumn{3}{|c|}{$\begin{array}{l}\text { Baseline samples analyzed in } \\
\text { 1968-1969 (same year) }\end{array}$} & \multicolumn{3}{|c|}{ Samples reanalyzed in 2012} & \multirow{2}{*}{$\begin{array}{c}\text { Median } \\
\text { percentage } \\
\text { change }(P)^{\mathrm{b}}\end{array}$} & \multirow{2}{*}{$\begin{array}{l}\text { Spearman } \\
\text { rho }(P)\end{array}$} \\
\hline & & Range & Median & Mean (SD) & Range & Median & Mean (SD) & & \\
\hline $\begin{array}{l}\text { Total cholesterol } \\
(\mathrm{mmol} / \mathrm{L})\end{array}$ & 26 & $5.1-7.9$ & 6.5 & $6.4(0.74)$ & $3.9-6.9$ & 5.3 & $5.4(0.79)$ & $-16.0^{* * *}$ & $0.86^{* * *}$ \\
\hline $\begin{array}{l}\text { Triglycerides } \\
(\mathrm{mmol} / \mathrm{L})\end{array}$ & 26 & $0.7-2.4$ & 1.0 & $1.1(0.43)$ & $0.8-2.6$ & 1.2 & $1.3(0.49)$ & $15.2^{* * *}$ & $0.90^{* * *}$ \\
\hline $\begin{array}{l}\text { Potassium } \\
(\mathrm{mmol} / \mathrm{L})\end{array}$ & 26 & $3.6-4.8$ & 4.1 & $4.1(0.32)$ & $3.6-5.0$ & 4.2 & $4.2(0.28)$ & $3.2^{* * *}$ & $0.89^{* * *}$ \\
\hline Insulin $(\mathrm{mU} / \mathrm{L})^{\mathrm{a}}$ & 29 & $3.0-47.0$ & 19 & $19.7(10.30)$ & $1.2-31.0$ & 7.8 & $10.5(8.70)$ & $-54.0^{* * *}$ & $0.74^{* * *}$ \\
\hline
\end{tabular}

${ }^{* * *} P<0.001$.

${ }^{\mathrm{a}}$ To convert from $\mathrm{mU} / \mathrm{L}$ to $\mathrm{pmol} / \mathrm{L}$ multiply by 6.945 .

${ }^{\mathrm{b}}$ Percentage of change was calculated as (level in 2012 - level at baseline)/level at baseline $* 100 \%$. $P$ values refer to the Wilcoxon signed rank test.

deviation. The agreement between the sets was explored through the intraperson percentage of change, calculated according to formula (1), and significance was tested with the Wilcoxon signed rank test. Consider

$$
\% \text { of change }=\frac{\text { level in } 2012-\text { level at baseline }}{\text { level at baseline }} * 100 .
$$

All analyses were carried out using the SAS Statistical Package Release 9.3 (SAS Institute, Cary, NC).

\section{Results}

Baseline levels were highly correlated with those in frozen serum, with Spearman's rho $>0.7$ on all markers (Table 2). Most of the variability in the 2012 remeasurements was explained by the baseline variability for cholesterol $\left(R^{2}=\right.$ $74 \%)$, triglycerides (88\%), potassium (76\%), and insulin (58\%) (Figure 1). 25(OH)D levels in 1968-1969 serum were strongly correlated with those in 1974-1975 serum, partial Spearman's rho $0.85(P<0.001)$. This correlation was 


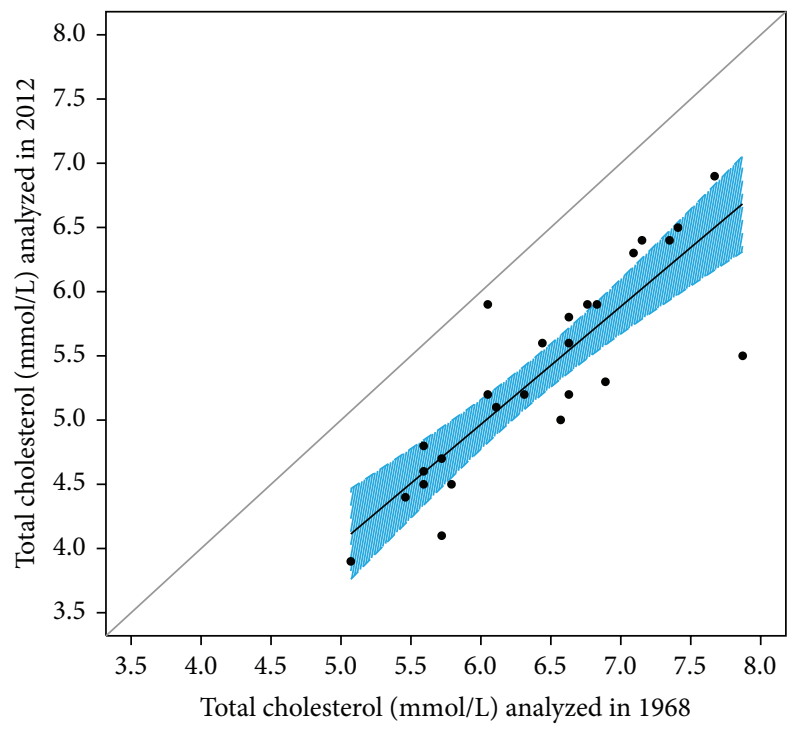

(a)

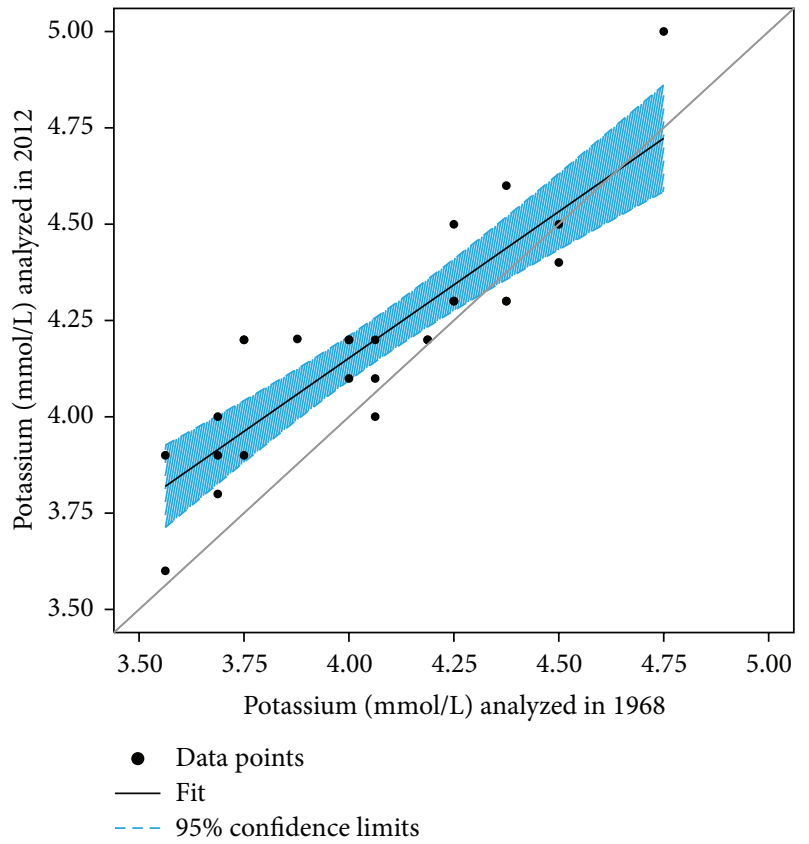

(c)

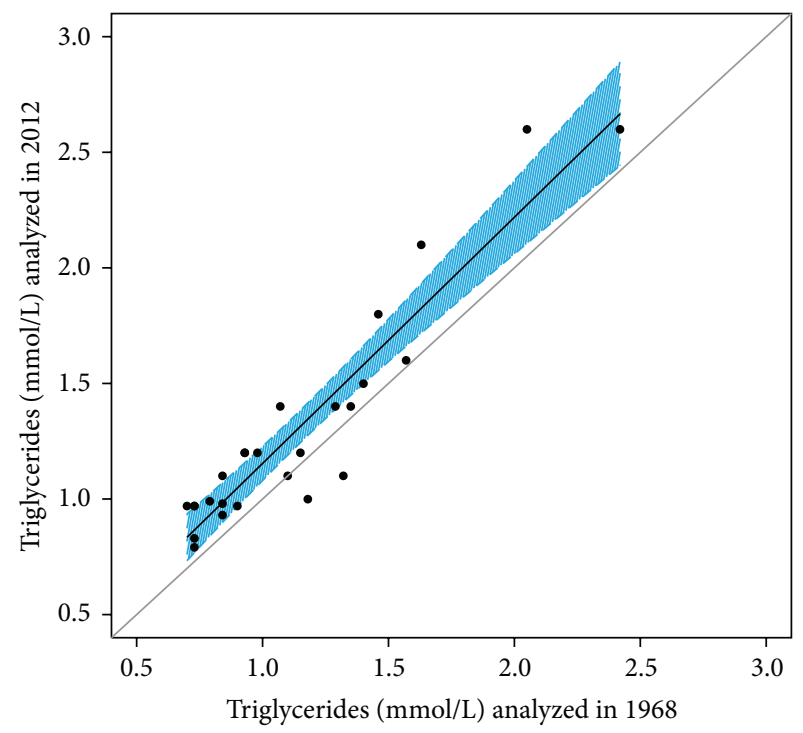

(b)

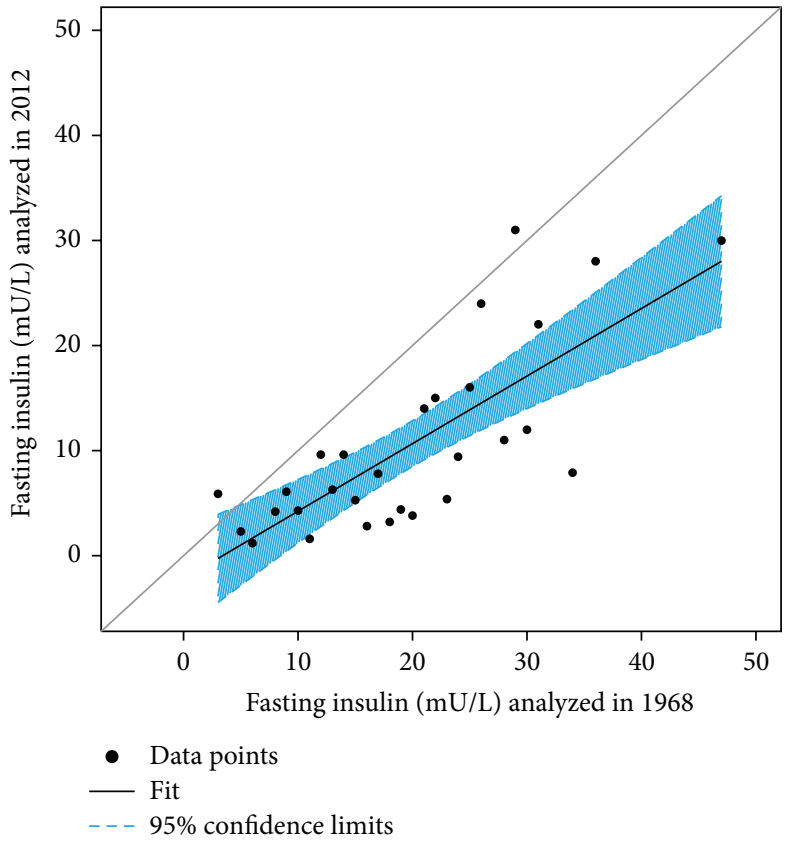

(d)

FIGURE 1: Correlation between 1968-1969 measurements and remeasurements in 2012 for total cholesterol (a), triglycerides (b), potassium (c), and insulin (d), with the original values on the $x$-axis and the remeasured values on the $y$-axis.

unchanged in the subjects with the same season of withdrawal. Also, $78 \%$ of the variability in the 1974-1975 serum was explained by levels in the 1968-1969 serum (Figure 2(a)). In additional models, we have also included the change in the month of sampling between the two examinations (modeled as a no/summer-to-winter/winter-to-summer change, yes/no, or the difference in calendar months) and BMI. After adjusting for the 1968-1969 levels, these factors did not further explain the variability in the 1974-1975 serum levels (data not shown).
In terms of absolute levels, total cholesterol and insulin in frozen serum decreased to $84 \%$ and $46 \%$, respectively, of the original concentration while triglycerides and potassium increased to $115 \%$ and $103 \%$ (Table 2). Vitamin D increased with a median $24 \%$ in the $1974-1975$ serum compared to the 1968-1969 serum (Table 3). Restricting the analysis to only those subjects with the same season of extraction at both examinations $(n=10)$ did not significantly change the results (median 18\%, $P<0.01$ ). For cholesterol, triglycerides, and potassium, the range of concentrations in reanalyzed samples 


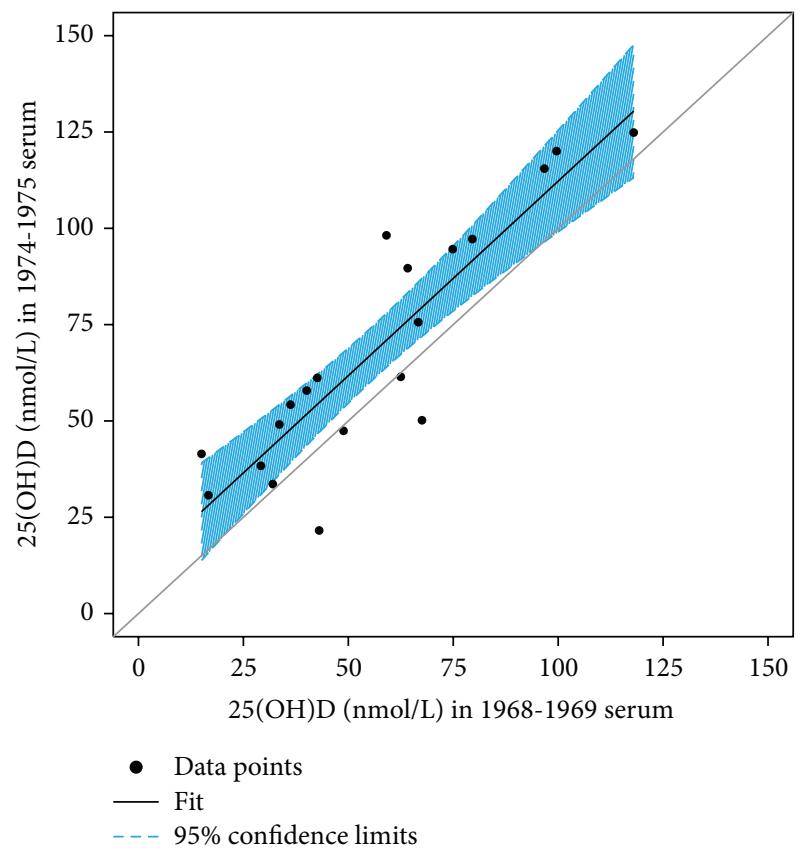

(a)

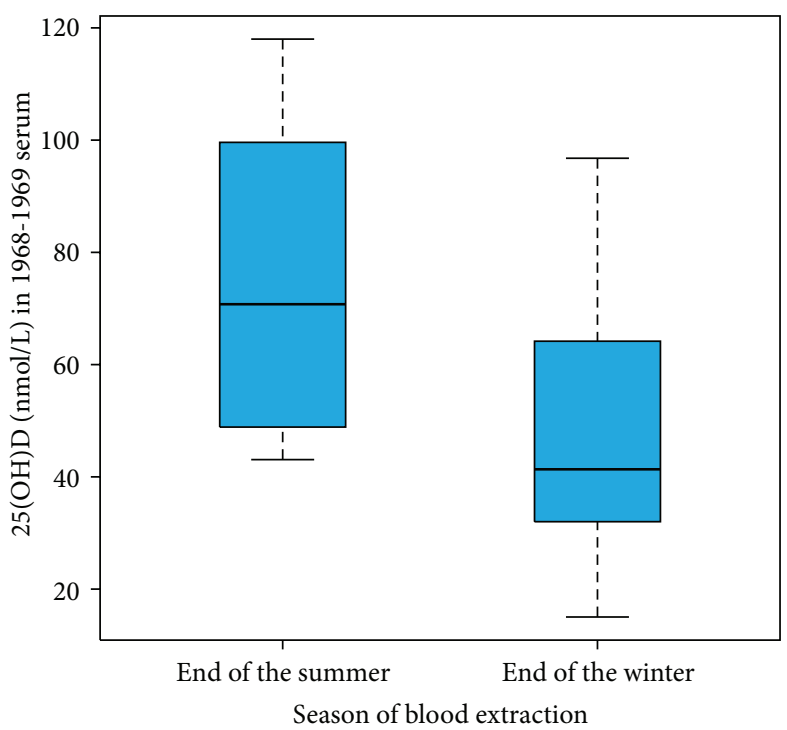

(b)

Figure 2: Comparisons between 25(OH)D levels in frozen serum between 1968-1969 and 1974-1975 from 20 subjects (a), and boxplot of $25(\mathrm{OH}) \mathrm{D}$ levels separately for samples collected at the end of the winter and at the end of the summer in 1968-1969 (b).

TABLE 3: Descriptive statistics, percentage of change, and correlation for vitamin D serum concentrations in frozen samples measured in 20 subjects at two time points 6 years apart.

\begin{tabular}{|c|c|c|c|c|}
\hline & $n$ & $25(\mathrm{OH}) \mathrm{D}(\mathrm{nmol} / \mathrm{L})$ in $1968-1969$ serum & 25(OH)D (nmol/L) in 1974-1975 serum & Percentage of change $^{\mathrm{a}}$ \\
\hline \multicolumn{5}{|l|}{ Mean (SD) } \\
\hline All & 20 & $56.3(27.86)$ & $68.1(31.61)$ & $30.7(45.88)$ \\
\hline End of summer & 6 & $75.2(29.07)$ & & \\
\hline End of winter & 14 & $48.2(23.97)$ & & \\
\hline \multicolumn{5}{|l|}{ Median } \\
\hline All & 20 & 54.0 & 59.5 & $24.2\left(\mathrm{P}=0.003^{\mathrm{b}}\right)$ \\
\hline End of summer & 6 & 70.8 & & \\
\hline End of winter & 14 & 41.4 & & \\
\hline \multicolumn{5}{|l|}{ Range } \\
\hline All & 20 & $15.0-118.0$ & $22.6-124.8$ & $-50.0-175.7$ \\
\hline End of summer & 6 & $43.1-118.0$ & & \\
\hline End of winter & 14 & $15.0-96.8$ & & \\
\hline
\end{tabular}

${ }^{\text {a }}$ Percentage of change was first calculated for each individual as (level in 1974-1975 serum - level in 1968-1969 serum)/(level in 1968-1969 serum) * 100\%.

${ }^{\mathrm{b}} P$ value is given according to the Wilcoxon signed rank test.

was similar to the range of the baseline values, while the 2012 insulin measurements were in a narrower interval compared to the original values (Table 2). For vitamin $\mathrm{D}$, all values were above the detection limit of $10 \mathrm{nmol} / \mathrm{L}$, ranging from 15 to $118 \mathrm{nmol} / \mathrm{L}$ in the 1968-1969 serum and exhibiting a similar fluctuation for the 1974-1975 serum (Table 3).

In the special case of vitamin $\mathrm{D}$, we investigated seasonal effects in the 1968-1969 serum (Table 3 and Figure 2(b)). A significant increase was found between the median value of subjects examined at the end of the winter, $41 \mathrm{nmol} / \mathrm{L}$, and among those examined at the end of the summer, $71 \mathrm{nmol} / \mathrm{L}$
(Mann-Whitney $U$ test, one-sided $P$ value $=0.02)$. Vitamin $\mathrm{D}$ levels correlated negatively with BMI (Spearman's rho = $-0.45, P=0.05)$.

\section{Discussion}

In the present study, we observed a high relative agreement between values assessed in fresh blood and values from frozen serum stored for over 40 years at $-20^{\circ} \mathrm{C}$ temperature, for total cholesterol, triglycerides, insulin, and potassium. In spite of some lack of absolute agreement, we found that 
the reanalyzed measurements were significantly correlated with the original values, as shown by correlation coefficients of 0.7 and larger. Vitamin D levels in frozen serum from two examinations six years apart were highly correlated $(0.85)$ and comparable with published levels on fresh blood $[13,17]$. Moreover, we detected summer to winter variation and a significant negative correlation with BMI.

Due to the different sampling strategies and/or the availability of baseline measurements in fresh blood, the biomarkers in this study can be grouped in three substudies, namely, total cholesterol, triglycerides, and potassium (substudy I), insulin (substudy II), and vitamin D (substudy III). For markers in substudy I, concentrations in fresh blood from the baseline and in stored serum were compared in 26 random subjects. To the best of our knowledge, our study is the first to validate biomarkers measured in serum stored for more than 40 years. In the literature, the storage time is usually at most 10 years. Among all markers, the concentration of potassium showed the smallest percentage of change (3\%). As an elementary ion, potassium is not subject to degradation and the relative increase of concentration is a measure of the evaporation of water from the tubes. The effect of 10 to 20 years of storage on potassium had been previously evaluated in other studies resulting in slight increases that were very similar to our findings $[16,18]$.

The cholesterol concentration was reduced (16\%), possibly due to degradation. Cholesterol has been previously found to decrease after few years in storage at $-70^{\circ} \mathrm{C}$ [19] or even to increase when stored at $-20^{\circ} \mathrm{C}[20]$. While similarly controversial findings are published on triglycerides stability, the increase we detected (15\%) is in line with the observation of an increase starting after 5 years in storage found by Shih et al. [19]. Nevertheless, in terms of the agreement between the two sets of measurements, we noticed positive correlations larger than 0.86 for both analytes. Kronenberg et al. [20] found an almost perfect correlation between measurements in fresh samples and samples stored for 2 years. These results indicate that the relative order of values is preserved for both total cholesterol and triglycerides.

Regarding insulin (substudy II), we have compared values in serum from baseline against assessments in fresh blood withdrawn within half a year from the baseline examination. Our analysis showed that, even though the concentration in the samples analyzed in 2012 was substantially decreased compared to the levels in fresh blood $(-54 \%)$, the two measurements were in high agreement, with a Spearman correlation coefficient of 0.74 . We could not find other published reports on the long-term effects of storage on insulin.

Our investigations on vitamin D (substudy III) are novel in regard to the stability of this analyte over a very long storage time (more than 40 years) and the preserved seasonal variability in frozen serum. First, it should be noted that, since vitamin $\mathrm{D}$ was not measured routinely when this biobank was established, we compare the absolute concentrations in our frozen samples with those in other Swedish studies using fresh blood [13, 17], both overall and season specific. Sääf et al. [17] found that, in women of Swedish ethnicity, the mean concentration was $66 \mathrm{nmol}$ (range $28-101 \mathrm{nmol}$ ) and
Brembeck et al. [13] found an overall mean of $47.4 \mathrm{nmol} / \mathrm{L}$ (range 10-93) nmol/L. The mean concentration in August and April was $69 \mathrm{nmol} / \mathrm{L}$ and $33 \mathrm{nmol} / \mathrm{L}$, respectively. These values are comparable with the ones in the current study, with an overall mean 56.3 (range 15-118) nmol/L, mean level in September $75.2 \mathrm{nmol} / \mathrm{L}$, and mean level in March-April $48.2 \mathrm{nmol} / \mathrm{L}$. Second, the relative agreement between the $25(\mathrm{OH}) \mathrm{D}$ measurements 6 years apart is consistent with published findings based on serum stored for several years only [21-23] through correlations very similar to ours. This implies that, in studies of chronic disease, vitamin D in material biobanked well before the onset can offer valuable clues regarding the future risk of disease. Similarly, this permits the exploration of within-individual changes in vitamin D status over time as a contributing factor to disease.

We also attempted to investigate the stability of sodium (data not shown) and found that the levels at reanalysis were significantly elevated as compared to those from fresh blood (range $144-148 \mathrm{mmol} / \mathrm{L}$ versus $134-145 \mathrm{mmol} / \mathrm{L}$ ) and that the two measurements were not correlated (Spearman's rho 0.12). Regrettably the original method of analysis was not documented and, therefore, these findings are not included in our main results. Another study [18] found that the sodium levels after 25 years of storage were significantly elevated compared to the initial levels. The increase in sodium concentration may be due to the evaporation of water in the tubes during storage.

This study is not without its limitations. The analyses are based on a relatively small sample size. For those analytes in substudy I, it is plausible that some of the differences in the measured concentrations may be due to methodological changes, including novel assay formats, instrumentation, and new lots of assay calibrators. Moreover, regarding insulin, the two measurements are assessed from blood samples at two time points within half a year from each other. Also, the vitamin $\mathrm{D}$ investigations are limited by the lack of baseline measurements; thus, it was not possible to determine the magnitude of change from the original values, but only to compare with known reference ranges and investigate correlations between levels in stored serum. In addition to a small sample size, another potential limitation is that the sample is not completely random as subjects were selected to reflect $25(\mathrm{OH}) \mathrm{D}$ seasonal variation. However, the high intraperson correlation, significant seasonal differences, and concentrations comparable with those assessed in fresh blood indicate that this marker is stable even with very prolonged storage. Furthermore, the findings in this study are strengthened by a unique long-term follow-up, population-based sampling and strong correlations despite small sample size.

\section{Conclusions}

Many longitudinal epidemiological studies collect biological specimens in biobanks. Prospective studies involving biobanked material offer valuable knowledge on how biomarkers contribute to disease etiology, provided that researchers can assess the validity of measurements after storage. 
The Population Study of Women in Gothenburg biobank is a unique resource with more than 40 years of storage and follow-up through examinations covering history of physical and mental disease, lifestyle, and social circumstances. Due to high participation rates and morbidity and mortality data, we can examine mid- to late-life outcomes. Our aim was to assess whether PSWG individuals can be ranked in future studies based on selected markers.

Except for the reduction in insulin levels, the changes in the absolute levels were minor compared to the original values, especially considering the extended storage time. Most importantly, the levels in two sample series were highly correlated which indicates that the relative order of values is preserved even for sample sets that have been biobanked during a long period. Notably, vitamin D levels were comparable with expected levels on fresh blood and preserved seasonal variability. Thus, it will be possible to include these biomarkers in studies of disease incidence in this cohort. Moreover, our findings may be useful to other investigators considering the use of long-term stored samples.

\section{Disclaimer}

The funding sources had no involvement in the study design, analysis of the data, or the writing of this report.

\section{Conflict of Interests}

The authors declare that there is no conflict of interests regarding the publication of this paper.

\section{Acknowledgments}

The authors gratefully acknowledge the financial support of the Swedish Research Council for Health, Working Life and Welfare (FORTE) and of the Gothenburg Center for Epidemiologic Studies on Mental and Physical Health Interacting over the Lifecourse (EpiLife). They also want to acknowledge the valuable help from the staff at the Section for Clinical Chemistry at Sahlgrenska University Hospital, Mölndal, as well as from the Biobanking and Molecular Resource Infrastructure of Sweden (BBMRI.se).

\section{References}

[1] A. Hofman, C. M. van Duijn, O. H. Franco et al., "The Rotterdam Study: 2012 objectives and design update," European Journal of Epidemiology, vol. 26, no. 8, pp. 657-686, 2011.

[2] P. Elliott and T. C. Peakman, "The UK Biobank sample handling and storage protocol for the collection, processing and archiving of human blood and urine," International Journal of Epidemiology, vol. 37, no. 2, pp. 234-244, 2008.

[3] C. M. Berg, L. Lissner, N. Aires et al., "Trends in blood lipid levels, blood pressure, alcohol and smoking habits from 1985 to 2002: results from INTERGENE and GOT-MONICA," European Journal of Cardiovascular Prevention and Rehabilitation, vol. 12, no. 2, pp. 115-125, 2005.

[4] C. Almqvist, H.-O. Adami, P. W. Franks et al., "LifeGene-a large prospective population-based study of global relevance," European Journal of Epidemiology, vol. 26, no. 1, pp. 67-77, 2011.
[5] L. Lind, S. Elmståhl, E. Bergman et al., "EpiHealth: a large population-based cohort study for investigation of genelifestyle interactions in the pathogenesis of common diseases," European Journal of Epidemiology, vol. 28, no. 2, pp. 189-197, 2013.

[6] D. E. Zylberstein, L. Lissner, C. Björkelund et al., "Midlife homocysteine and late-life dementia in women. A prospective population study," Neurobiology of Aging, vol. 32, no. 3, pp. 380386, 2011.

[7] D. E. Zylberstein, C. Bengtsson, C. Björkelund et al., "Serum homocysteine in relation to mortality and morbidity from coronary heart disease: a 24-year follow-up of the population study of women in Gothenburg," Circulation, vol. 109, no. 5, pp. 601-606, 2004.

[8] C. Bengtsson, G. Blohmé, L. Hallberg et al., "The study of women in Gothenburg 1968-1969-a population study. General design, purpose and sampling results," Acta Medica Scandinavica, vol. 193, no. 4, pp. 311-318, 1973.

[9] L. Lissner, I. Skoog, K. Andersson et al., "Participation bias in longitudinal studies: experience from the Population Study of Women in Gothenburg, Sweden," Scandinavian Journal of Primary Health Care, vol. 21, no. 4, pp. 242-247, 2003.

[10] G. Blohmé, "Intravenous glucose tolerance and early insulin response. Studies on a random sample of women aged 50 and patients with diabetes mellitus," Acta Medica Scandinavica, vol. 566, pp. 1-121, 1974.

[11] E. Hyppönen and C. Power, "Hypovitaminosis D in British adults at age $45 \mathrm{y}$ : nationwide cohort study of dietary and lifestyle predictors," American Journal of Clinical Nutrition, vol. 85, no. 3, pp. 860-868, 2007.

[12] J. Klenk, K. Rapp, M. D. Denkinger et al., "Seasonality of vitamin $\mathrm{d}$ status in older people in Southern Germany: implications for assessment," Age and Ageing, vol. 42, no. 3, Article ID aft042, pp. 404-408, 2013.

[13] P. Brembeck, A. Winkvist, and H. Olausson, "Determinants of vitamin D status in pregnant fair-skinned women in Sweden," British Journal of Nutrition, vol. 110, no. 5, pp. 856-864, 2013.

[14] J. B. Levine and B. Zak, "Automated determination of serum total cholesterol," Clinica Chimica Acta, vol. 10, no. 4, pp. 381384, 1964.

[15] H. B. Lofland Jr., "A semiautomated procedure for the determination of triglycerides in serum," Analytical Biochemistry, vol. 9, no. 4, pp. 393-400, 1964.

[16] E. Rybo, C. Bengtsson, L. Hallberg, G. Lindstedt, and P. A. Lundberg, "Serum ferritin concentration compared to other iron-store variables in the diagnosis of iron deficiency," Scandinavian Journal of Haematology, vol. 43, pp. 87-102, 1985.

[17] M. Sääf, E. Fernell, F. Kristiansson, M. B. Olsson, S. A. Gustafsson, and G. Bågenholm, "Severe vitamin D deficiency in pregnant women of Somali origin living in Sweden," Acta Paediatrica, vol. 100, no. 4, pp. 612-614, 2011.

[18] R. E. Gislefoss, T. K. Grimsrud, and L. Mørkrid, "Long-term stability of serum components in the Janus Serum Bank," Scandinavian Journal of Clinical \& Laboratory Investigation, vol. 68, no. 5, pp. 402-409, 2008.

[19] W. J. Shih, P. S. Bachorik, J. A. Haga, G. L. Myers, and E. A. Stein, "Estimating the long-term effects of storage at $-70^{\circ} \mathrm{C}$ on cholesterol, triglyceride, and HDL-cholesterol measurements in stored sera," Clinical Chemistry, vol. 46, no. 3, pp. 351-364, 2000.

[20] F. Kronenberg, E.-M. Lobentanz, P. König, G. Utermann, and H. Dieplinger, "Effect of sample storage on the measurement 
of lipoprotein[a], apolipoproteins B and A-IV, total and high density lipoprotein cholesterol and triglycerides," Journal of Lipid Research, vol. 35, no. 7, pp. 1318-1328, 1994.

[21] M. C. Ocke, J. Schrijver, G. L. Obermann-de Boer, B. P. M. Bloemberg, G. R. M. M. Haenen, and D. Kromhout, "Stability of blood (pro)vitamins during four years of storage at $-20^{\circ} \mathrm{C}$ : consequences for epidemiologic research," Journal of Clinical Epidemiology, vol. 48, no. 8, pp. 1077-1085, 1995.

[22] L. Rejnmark, A. L. Lauridsen, C. Brot et al., "Vitamin D and its binding protein Gc: long-term variability in peri- and postmenopausal women with and without hormone replacement therapy," Scandinavian Journal of Clinical \& Laboratory Investigation, vol. 66, no. 3, pp. 227-238, 2006.

[23] W. Saliba, O. Barnett, N. Stein, A. Kershenbaum, and G. Rennert, "The longitudinal variability of serum 25(OH)D levels," European Journal of Internal Medicine, vol. 23, no. 4, pp. e106el11, 2012. 


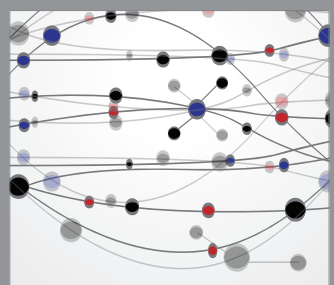

The Scientific World Journal
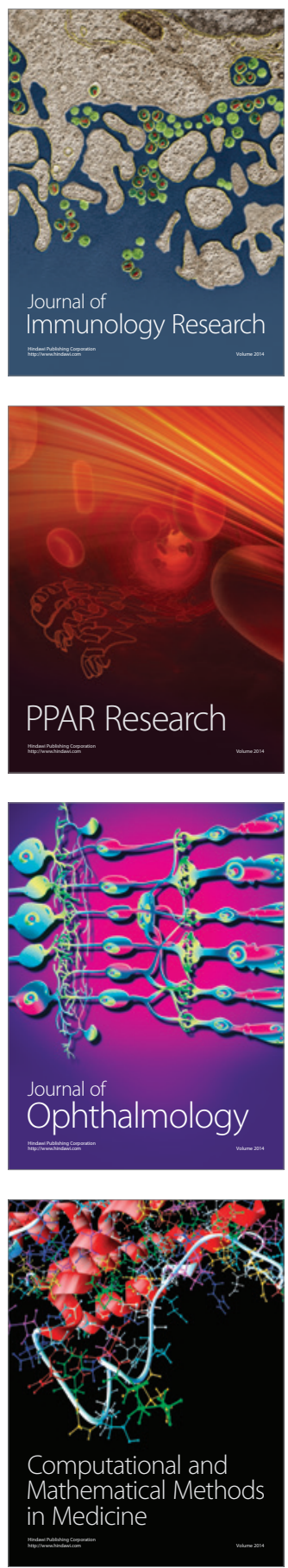

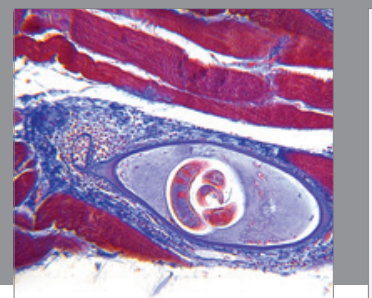

Gastroenterology

Research and Practice
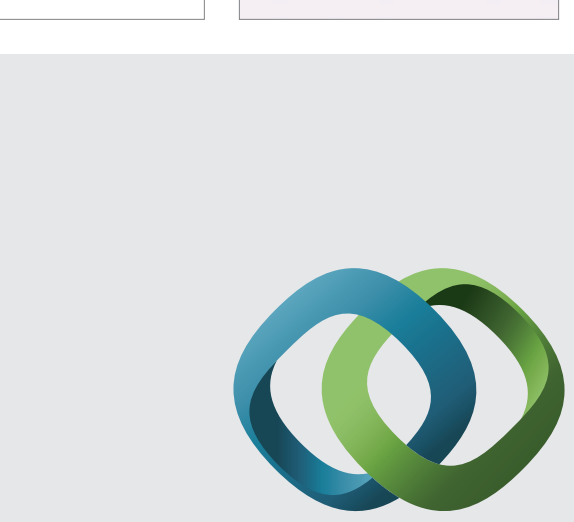

\section{Hindawi}

Submit your manuscripts at

http://www.hindawi.com
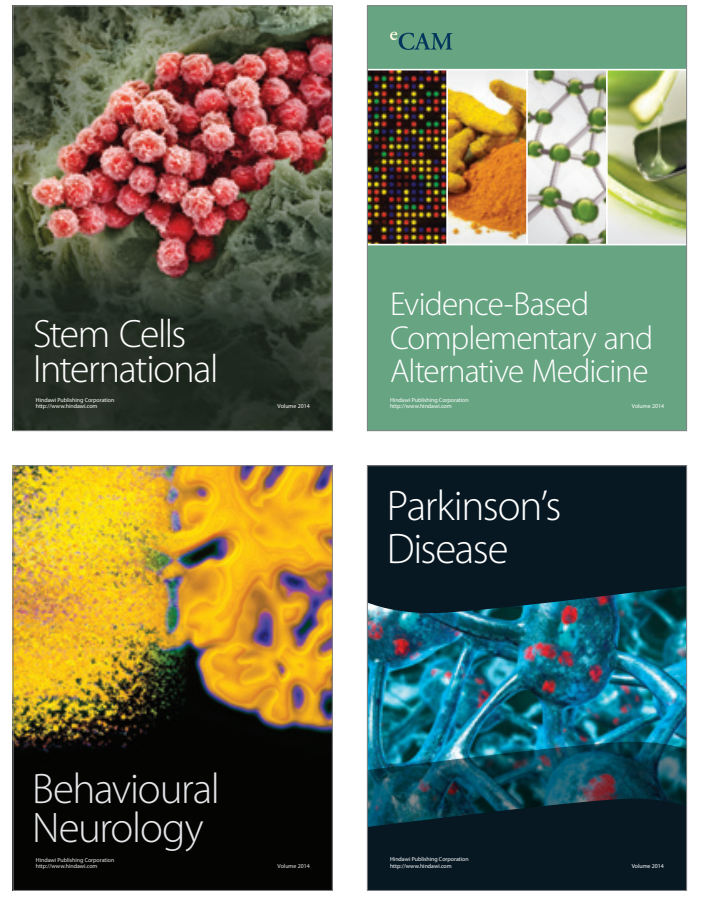
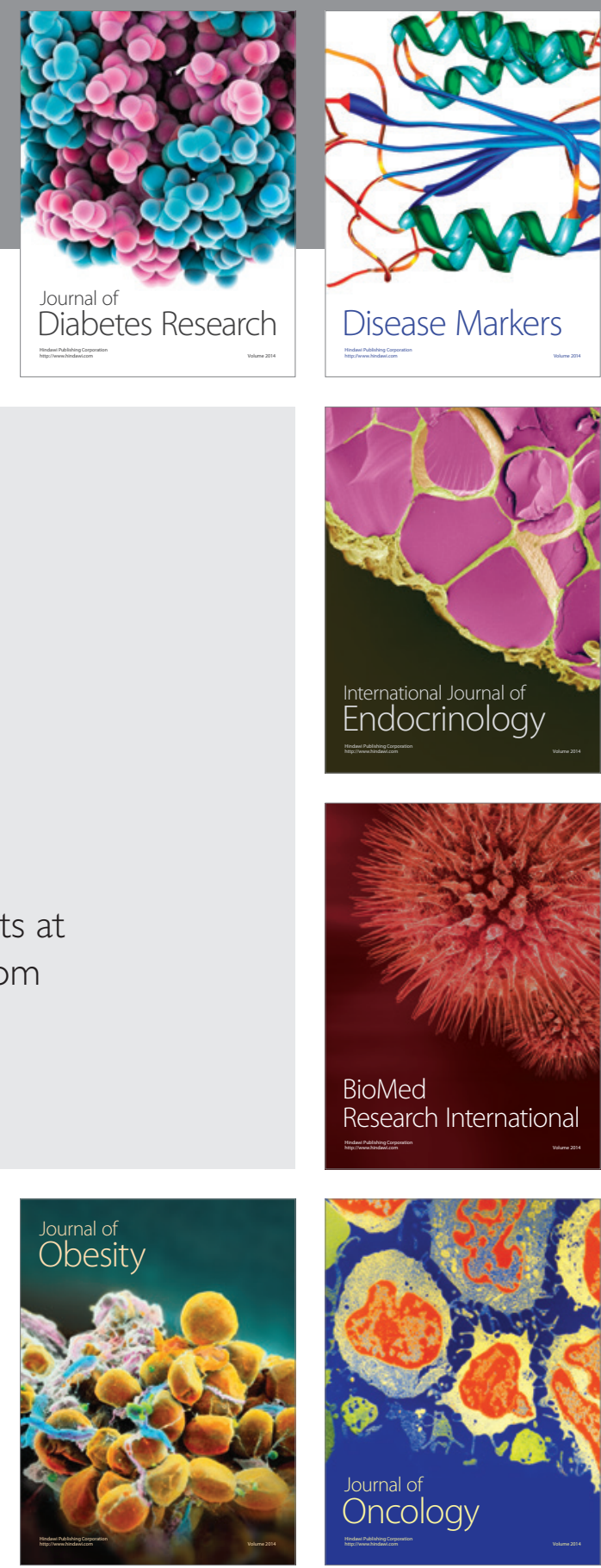

Disease Markers
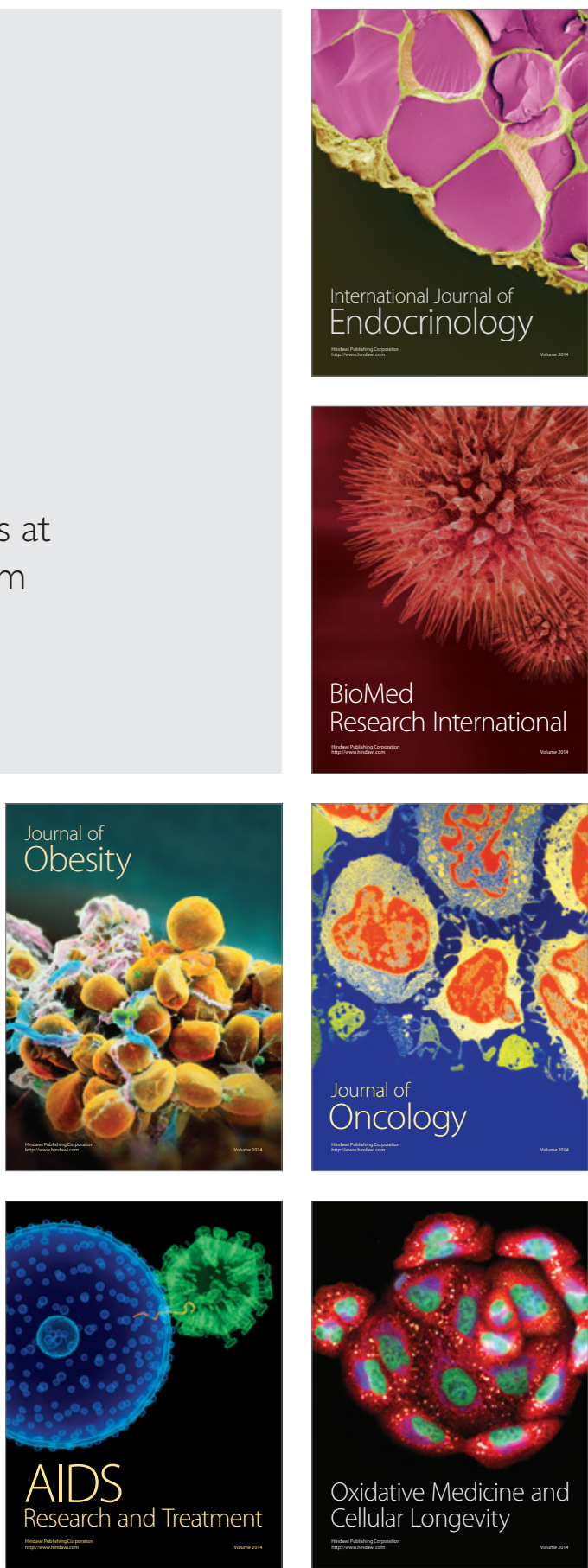